\title{
DESENVOLVIMENTO SUSTENTÁVEL LOCAL NA SOCIEDADE EM REDE: OPOTENCIALDAS NOVAS TECNOLOGIAS DE INFORMAÇÃO E COMUNICAÇÃO ${ }^{1}$
}

\author{
Klaus Frey
}

RESUMO

Face às crescentes críticas aos modelos predominantes de desenvolvimento voltados ou para soluções de mercado ou para ações estatais centralizadoras e impositivas, este trabalho propõe uma investigação teórica das possibilidades de fomentar um desenvolvimento local mais sustentável através do fortalecimento de redes sociais e sua inserção progressiva nos processos político-administrativos locais. Partindo de uma leitura crítica da concepção do capital social, o artigo evidencia a importância de estratégias de desenho institucional capazes de mobilizar o capital social e garantir às comunidades locais acesso ao poder social e político. Na seqüência, e considerando as condições sociais e políticas específicas do Brasil, o texto discute as possibilidades e dilemas do uso das novas tecnologias de informação e comunicação para revigorar processos de coordenação social no âmbito das comunidades locais e para revitalizar a participação comunitária na gestão pública local. Por fim, discute-se o novo papel exigido pelos governos locais visando explorar de maneira efetiva a opção comunitária para promover o desenvolvimento sustentável na emergente sociedade em rede.

PALAVRAS-CHAVE: capital social; redes comunitárias; política local; sociedade em rede; desenvolvimento sustentável.

\section{INTRODUÇÃO}

Em função dos programas de ajuste estrutural implementados em boa parte dos países nas últimas décadas, envolvendo políticas de austeridade, desregulação, privatização e uma retração geral do Estado da esfera econômica, o setor público está sofrendo grandes transformações, sobretudo um aumento da dependência das decisões de agentes econômicos privados. Nas cidades, particularmente nos países em desenvolvimento, observase uma crescente perda de governabilidade. Faltam condições e ferramentas adequadas de gestão para implementar iniciativas efetivas de desenvolvimento local, capazes de promover um desenvolvimento sustentável no âmbito das comu-

\footnotetext{
1 Uma versão preliminar deste artigo foi apresentada no Grupo de Trabalho "Sociedade da Informação: redes sociais, fundamentos da sociabilidade e transformações dos processos políticos", no XXVI Encontro Anual da Associação Nacional de Pesquisa e Pós-Graduação em Ciências Sociais (ANPOCS), realizado em Caxambu (MG), de 22 a 26 de outubro de 2002.
}

nidades locais, respeitando as exigências de justiça social. Faltam estruturas e instituições de governança local apropriadas para estimular a ação coletiva e articular os diferentes atores locais em torno de objetivos comuns de desenvolvimento local.

Os recentes processos de transformação econômica e social parecem exigir novos modelos inovadores de gerenciamento, assim como novos instrumentos, procedimentos e formas de ação capazes de criar condições favoráveis que auxiliem os administradores públicos a lidar com os novos desafios da sociedade globalizada.

Entretanto, a crescente complexidade dos processos locais de tomada de decisão e uma agenda urbana cada vez mais ampliada - tornando mais relevantes temas como o desenvolvimento econômico local, a geração de emprego, a segurança pública e a poluição e deterioração ambiental revelaram a incapacidade das instituições políticas e administrativas locais em lidar com esses novos desafios para as políticas públicas locais.

Perante a percepção de uma aparente inca- 
pacidade sistêmica do setor público em enfrentar os efeitos negativos da globalização, dos mercados livres e de sistemas enfraquecidos de segurança social, a "community option" (CLAVEL, PITT \& YIN, 1997) apresenta-se como uma alternativa promissora, particularmente em nível local, às estratégias tradicionais baseadas ou na ação centralizada do Estado ou nas soluções de mercado. Neste trabalho estamos investigando a perspectiva das comunidades como possíveis agentes de transformação no contexto da atual sociedade da informação ou "sociedade em rede", levando em consideração as condições de governos locais em países em desenvolvimento e, particularmente, no Brasil.

Um ponto de partida importante para a nossa reflexão é a concepção da sociedade em rede de Manuel Castells, segundo a qual a sociedade moderna é caracterizada pela predominância da forma organizacional da rede em todos os campos da vida social (CASTELLS, 1999; 2000; 2001). Conforme a interpretação de Castells, os grupos sociais mais poderosos adaptam-se de maneira cada vez melhor às novas condições da sociedade da informação, utilizando as novas potencialidades abertas pela globalização e pelo acesso às novas tecnologias da informação e comunicação (TICs) em prol da consolidação de suas identidades grupais e do fortalecimento de sua capacidade de agir em um mundo cada vez mais interdependente. Essa situação, no entanto, contrasta fortemente com os processos de fragmentação e segmentação que se observa entre os setores sociais mais fragilizados da sociedade, particularmente no nível comunitário dos países em desenvolvimento. No contexto brasileiro, em que os novos processos e dinâmicas da sociedade em rede - mais nítidos e vigorosos nos países econômica e tecnologicamente mais desenvolvidos - convivem com padrões tradicionais da vida social e econômica e em que prevalecem fortes tendências de exclusão social e digital, o surgimento da sociedade em rede parece reforçar ainda mais a exclusão social, política e econômica, afrouxando os laços sociais no nível comunitário e colocando em risco a própria democracia.

Colocam-se, portanto, as seguintes questões: como a opção comunitária pode ser explorada em um contexto de exclusão social e marginalização? Quais os ingredientes necessários para tornar as comunidades locais mais vitais e aptas para agir de maneira coletiva em prol do bem comum? Como condições externas promovem ou impedem o desenvolvimento comunitário?

Este trabalho propõe uma investigação teórica das concepções de capital social, desenho institucional e rede social no que tange à sua relevância para a compreensão do papel de redes comunitárias em processos políticos locais e para as potencialidades das TICs e de comunidades virtuais de impulsionar o desenvolvimento de tais redes. As concepções teóricas são questionadas a partir da perspectiva das condições sociais e políticas brasileiras. Ênfase especial é dada às possibilidades de usar a internet como um meio para o fortalecimento das comunidades locais e das práticas democráticas. Nas considerações finais, serão discutidos os principais desafios e dilemas para explorar de maneira efetiva a opção comunitária para promover o desenvolvimento sustentável na emergente sociedade em rede.

\section{CAPITAL SOCIAL}

A concepção de capital social recebeu grande destaque a partir do debate sobre desenvolvimento local desencadeado pela publicação do livro Making Democracy Work, de Robert Putnam, em 19932. Nesse estudo sobre os fundamentos da democracia italiana, Putnam identificou uma grande densidade de associações e a existência de relações sociais de reciprocidade como as principais premissas de uma democracia vital e de um engajamento cívico efetivo. Estes fatores não apenas garantem o caráter democrático da sociedade civil, mas também determinam o desempenho dos governos locais e de suas instituições. Em analogia aos conceitos de capital financeiro e capital humano, para Putnam o "“capital social' refere-se a elementos de organização social como as redes, normas e confiança social que facilitam a coordenação e a cooperação em benefício recíproco" (PUTNAM, 1995, p. 67). No intenso debate que se seguiu o capital social foi considerado de fundamental importância não apenas para a consolidação da democracia (PUTNAM, 1995; 2000a; 2000b; ver também: WILSON, 2001), mas também para uma efetiva governança local e urbana (MALONEY, SMITH \& STOKER, 2000; LOWNDES \& WILSON, 2001), para sustentar redes de inovação tecnológica e de políticas públicas (WEYER, 2000), para o desenvolvimento comunitário e social (ETZIONI, 2001; BRINT,

\footnotetext{
2 A versão em português foi publicada sob o título: Comunidade e democracia (PUTNAM, 2000a).
} 
2001), para a implementação de projetos de democracia eletrônica e de comunidades virtuais (BLANCHARD \& HORAN, 1998; COLEMAN \& GOTZE, 2002) e, finalmente, para a proteção do meio ambiente e o uso sustentável dos recursos naturais (PRETTY \& WARD, 2001). Isto é, sempre que o individualismo e o comportamento de escolha racional, que predomina no sistema de mercado, chegarem a exercer seus "efeitos cancerígenos sobre a vida comunitária" (TAM, 1998, p. 3), minando a possibilidade de alcançar metas coletivas, ou, ainda, quando organizações burocráticas são identificadas como impedimentos de inovação, advoga-se abordagens de capital social em função de seu possível potencial para a superação dos efeitos negativos do liberalismo econômico.

Em seu estudo sobre a Itália (PUTNAM, 2000a) e em seu mais recente livro sobre a sociedade americana, Bowling Alone: The Collapse and Revival of American Community (PUTNAM, 2000b), Putnam coletou evidências empíricas significativas que parecem confirmar a suposta correlação entre engajamento cívico e o desempenho das instituições governamentais e sociais. Para Putnam capital social é sinônimo da existência de confiança social, normas de reciprocidade, redes de engajamento cívico e, finalmente, de uma democracia saudável e vital. Segundo ReeseSchäfer (2001), por meio de sua fundamentação empírico-científica da tese da erosão do engajamento cívico público, Putnam está contribuindo para as preocupações concernentes à atomização progressiva da sociedade contemporânea, que são particularmente fortes na vertente teórica do comunitarismo. Sobretudo em seu recente estudo sobre o declínio das comunidades americanas, baseado em um material estatístico expressivo, Putnam detectou um crescente desinteresse dos cidadãos americanos em questões relacionadas às comunidades locais. O diagnóstico constata um declínio generalizado do engajamento político, taxas decrescentes de participação em eleições, em encontros públicos sobre questões referentes a cidades ou escolas, a redução de todo tipo de engajamento direto em questões políticas e governamentais e a diminuição da disposição de associar-se a partidos políticos e outras organizações sociais e políticas locais. Esse declínio do engajamento cívico estende-se ao envolvimento em grupos religiosos, sindicatos de trabalho, associações de pais e professores e outros tipos de organizações cívicas e fraternais.
De acordo com Putnam, essas organizações básicas da vida social são essenciais para o estabelecimento de normas e padrões comuns, para a promoção de confiança social e interpessoal e, no final, para o crescimento do engajamento cívico. A suposição básica de Putnam é que membros de associações tendem a ser política e socialmente mais ativos, dando apoio às normas democráticas. Isto significa que a densidade de todos os tipos de associações em uma dada sociedade representa o seu estoque de confiança e reciprocidade, isto é, seu estoque de capital social. Como conseqüência, Putnam assume que o capital social pode ser medido por meio do levantamento quantitativo do envolvimento e da participação em associações (GRIX, 2001, p. 193).

As objeções contra a concepção de Putnam são variadas ${ }^{3}$. A seguir gostaria de levantar alguns aspectos dessas críticas que são particularmente relevantes do ponto de vista de países em desenvolvimento, caracterizados por grandes fricções e desigualdades sociais e condições culturais peculiares.

Adotando uma abordagem basicamente quantitativa, Putnam enfrenta o dilema de como tratar os diferentes tipos de associações, cujas particularidades são ignoradas nas pesquisas existentes. Assim, ser membro de um clube de boliche ou de uma escola de samba é certamente algo muito diferente do que ser membro de um partido político ou de uma associação de moradores, sobretudo em termos de exercício de cidadania. Apesar de todos os tipos de associações, em princípio, contribuírem para aumentar as conexões sociais, existe uma diferença muito significativa entre associações cujos objetivos limitam-se a praticar atividades de lazer ou ritos religiosos, de um lado, e associações engajadas na solução de questões públicas e problemas da coletividade, de outro. Ainda mais curioso certamente seria a idéia de que organizações "sociais" como, por exemplo, o Comando Vermelho nas favelas do Rio de Janeiro, o Primeiro Comando da Capital de São Paulo, ou até a rede terrorista Al Caida - que certamente contribuem para o aumento do grau de conectividade nas suas respectivas populações, e, com isso, seguindo a interpretação de Putnam, aumentam o capital social

\footnotetext{
3 Ver por exemplo o artigo de Grix (2001) sobre a concepção de capital social.
} 
-, representam uma contribuição para o fortalecimento da cultura cívica ${ }^{4}$.

Outro ponto crítico refere-se à suposição implícita na concepção de Putnam de que ser membro formal de uma associação significa, pelo menos até um certo nível, ser membro efetivo e atuante. Nas sociedades ocidentais é um fato bastante conhecido a participação, de forma passiva, em igrejas e associações religiosas, freqüentemente resultado de uma pressão social e moral existente que torna o não-pertencimento às igrejas dominantes um empecilho à ascensão social. Em contrapartida, observa-se em países em desenvolvimento como o Brasil exatamente o contrário: pessoas, engajadas em atividades de grupos comunitários ou religiosos, mas sem pertencerem à categoria de membros formais de tais organizações. Desse ângulo, esse tipo de análise quantitativa, que já deve ser considerado crítico no contexto das sociedades industriais consolidadas, torna-se ainda mais questionável em países em desenvolvimento, caracterizados pela pouca tradição em associacionismo formal e, com isso, a abordagem de Putnam parece pouco apropriada para esclarecer as condições do engajamento cívico em tais países.

Levando em consideração, além disso, que o ativismo associativo é mais característico das classes médias com nível educacional mais elevado, é preciso estar ciente de que, sobretudo no contexto de desorganização social e de grandes desigualdades, a busca pelo capital social nas organizações civis tradicionais pode mostrar-se um empreendimento pouco útil. Freqüentemente, as organizações tradicionais da classe média são conservadoras, capazes de sustentar uma ordem

\footnotetext{
4 Apesar de Putnam (2000b) reconhecer essa ambigüidade inerente ao capital social, dedicando inclusive um capítulo inteiro a esse suposto "lado escuro do capital social", ele rejeita essa percepção mais cética de cunho liberal, ao remeter aos surveys realizados ao longo das últimas décadas que, segundo ele, todos confirmariam sua tese do impacto gerador de solidariedade do capital social. Sua avaliação não deixa sombra de dúvidas, tanto no que tange à questão da liberdade e tolerância - "eu não encontrei nem um único estudo empírico que confirma o suposto vínculo entre envolvimento comunitário e intolerância" (idem, p. 355), concluindo que "capital social e tolerância têm uma relação simbiótica" -, quanto no que diz respeito à questão da igualdade: "Comunidade e igualdade reforçam-se mutuamente e não são mutuamente incompatíveis" (idem, p. 358).
}

social dada, mas raramente dispostas a contribuir para a transformação social. Particularmente nos países em desenvolvimento, as associações civis tendem a reforçar as desigualdades existentes, as estruturas paternalistas e hierárquicas e privilégios sociais e até a conviver com a corrupção.

Com sua ênfase em redes baseadas em associações cívicas tradicionais, o estudo empírico de Putnam dá apoio à versão mais conservadora do comunitarismo, que, ainda no início dos anos 1980, advogou uma moralidade mais homogênea, reclamando validade para toda a sociedade (VAN DEN BRINK, 1995, p. 16). As organizações e associações que Putnam considera mais adequadas para a promoção do espírito comunitário são exatamente aquelas que tendem a ser mais excludentes, a defender e preservar a ordem e os privilégios existentes e que muitas vezes trabalham em prol da privatização dos espaços e questões públicos. Observa-se, sobretudo nos Estados Unidos, uma aliança estratégica entre comunitarismo e neoliberalismo, que ganhou influência expressiva tanto no campo da teoria como na vida política e social e que defende o fortalecimento das comunidades, acima de tudo, com o intuito de mitigar os efeitos sociais nocivos da liberalização econômica e da desestatização. Desse ângulo, a aposta nas comunidades locais, nas associações sociais e no terceiro setor pode também ser vista como meio de compensação indispensável para garantir a continuidade do processo de transformação econômico-social iniciado como o projeto neoliberal.

Enquanto, em princípio, todo tipo de ativismo por parte de associações pode mostrar-se importante para praticar e experimentar comportamentos sociais e atitudes de solidariedade, observa-se que muitas vezes essas oportunidades são apenas proporcionadas aos correligionários que compartilham os mesmos interesses e visões de mundo. Esses tipos de associações não necessariamente contribuem para a tolerância e uma melhor compreensão de outros e da diferença, o que se faz tão necessário em nosso mundo cada vez mais complexo e diversificado, sobretudo em países em desenvolvimento, ainda mais do que nas sociedades ocidentais com democracias consolidadas e economias mais desenvolvidas, caracterizadas por um certo grau de homogeneidade e coesão social, a questão de como lidar com as diferenças torna-se crucial. 
Nesses países os processos políticos costumam comportar mais conflitos em função das profundas fricções existentes entre os grupos e classes sociais. No contexto da estrutura hierárquica de dominação que reina nesses países colocam-se as seguintes questões: existem possibilidades de contribuir para a resolução de conflitos sociais por meio do fortalecimento das comunidades locais e sem, necessariamente, seguir o modelo habitual caracterizado pela cooptação dos pobres pela elite tradicional? Podem as comunidades locais tornar-se atores relevantes em um processo de contestação e transformação social, estimulando um processo de emancipação individual e coletivo?

Perante esse desafio é evidente que não podemos limitar nossas investigações à densidade das associações, mas que precisamos levar em consideração os tipos de associações e grupos sociais, a profundidade do envolvimento dos cidadãos em tais grupos, assim como a qualidade da relação estabelecida entre os cidadãos e grupos sociais, de um lado, e os governos e administrações públicas, de outro (MALONEY, SMITH \& STOKER, 2000; LOWNDES \& WILSON, 2001). Com isso, surgem novas perguntas: em que medida as organizações cidadãs são capazes de desempenhar um papel significativo em processos políticos de tomada de decisão, sobretudo na luta contra as elites dominantes e em processos visando ao fortalecimento de comunidades locais? Existem focos ou formas de organizações cidadãs capazes de superar as tendências de fragmentação e atomização que caracterizam as comunidades locais no nível de vizinhança? E como tais organizações podem efetivamente influenciar processos políticos de tomada de decisão?

No Brasil, as organizações cívicas tradicionais não são vistas - pelo menos não por parte das Ciências Sociais - como atores muito promissores nesses processos, ao passo que as expectativas costumam ser mais direcionadas para os movimentos sociais, os quais desempenharam um papel fundamental no processo de democratização (CARDOSO, 1994).

Putnam também considera os movimentos sociais como uma das tendências contrárias ao declínio geral do capital social nos Estados Unidos. Entretanto, em comparação com as associações cívicas tradicionais com raízes fortes nas comunidades locais, ele vê no fortalecimento dos movimentos sociais e das organizações do terceiro setor uma deterioração qualitativa, alegando que muitas dessas novas relações sociais não passariam de afiliações de "talão de cheque" (PUTNAM, 2000b, p. 158). Segundo Putnam, "tais organizações não providenciam nem conexão entre membros, nem engajamento direto em uma forma cívica do dar-e-receber, e certamente elas não representam 'democracia participativa'. Cidadania por representação é um oximoro" (idem, p. 160).

As principais objeções de Putnam contra os movimentos sociais e as organizações do terceiro setor, enquanto fontes primordiais do capital social, baseiam-se na suposição segundo a qual os laços e obrigações que une os membros desses movimentos seriam mais fracos do que em organizações tradicionais. De acordo com Putnam, é a vida social, o contato face-a-face que mantém unidas as sociedades e não o ativismo político em movimentos sociais, a participação em associações do terceiro setor, a colaboração em organizações sem fins lucrativos ou o envolvimento em grupos de ajuda. Segundo Putnam, esses tipos de grupos falham no concernente à sua mais importante tarefa: a promoção de confiança social.

Do ponto de vista brasileiro, podemos levantar pelo menos duas objeções: Em primeiro lugar, movimentos sociais como o Movimento dos Trabalhadores Rurais Sem Terra (MST) ou organizações não-governamentais como a Pastoral da Criança certamente não são, como Putnam alega, desconectados da sua base social. Ao contrário, e apesar de certas contradições que tais experiências sempre acarretam, são novas formas emergentes de vida social e de engajamento político, capazes não apenas de renovar os laços sociais das comunidades, mas também de promover novas formas de participação pública visando à transformação das condições sociais e políticas. De fato, tais organizações atuam localmente, mas, ao mesmo tempo, procuram reconhecimento em âmbito nacional e até internacional. Adotando a categorização de Manuel Castells, podemos enquadrá-los até nos "mais influentes movimentos sociais [que], simultaneamente, são enraizados no seu contexto local e visam a alcançar impacto global. Eles necessitam da legitimidade e do apoio provido pela relação de confiança estabelecida com grupos locais; contudo, não podem permanecer locais, ou perdem sua capacidade de agir sobre as fontes reais de 
poder em nosso mundo" (CASTELLS, 2001, p. 143).

Em segundo lugar, o declínio das organizações civis convencionais não precisa necessariamente ser interpretado como um mero declínio do engajamento cívico, mas pode representar um novo entendimento de engajamento cívico e o reconhecimento da necessidade de reinventar as formas de ativismo e envolvimento cívico em uma sociedade crescentemente complexa, pluralista e - certamente também - individualista. Em lugar de apostar exclusivamente nos grupos de interesse, que costumam defender apenas interesses grupais e tendem a promover condições de coesão e exclusão, simultaneamente, talvez seja pertinente pensar nas potencialidades de novas formas de organização e ação política capazes de promover tolerância, diálogo, compreensão mútua, pontes entre os diferentes grupos sociais, mas também, se for necessário, pressão, contestação e luta contra as injustiças existentes na sociedade contemporânea.

Alguns observadores do processo de democratização no Brasil chegaram a uma avaliação positiva e otimista da atuação das organizações da sociedade civil no processo social e político. Segunda Vera Telles, a sociedade civil assumiu progressivamente responsabilidade no que diz respeito à "constituição de espaços públicos nos quais as diferenças podem se expressar e se representar em uma negociação possível" (TELLES, 1994, p. 92) e "nos quais os conflitos ganham visibilidade e as diferenças se representam nas razões que constroem os critérios de validade e legitimidade dos interesses e aspirações defendidos como direitos" (idem, p. 101). Isso significa que, de uma perspectiva emancipadora, a abordagem de Putnam sobre o capital social mostra-se equivocada na medida em que a ênfase é dada na mera densidade das organizações cívicas convencionais, negligenciando os avanços nas práticas e padrões de atuação política por parte dos novos grupos sociais. Desse ponto de vista, merecem maior atenção os movimentos e organizações politicamente relevantes e a sua capacidade de promover redes sociais e cívicas, bem como os fatores institucionais e a qualidade das relações estabelecidas entre os grupos intermediários em uma sociedade e entre associações sociais e poder público (GRIX, 2001, p. 197). As qualidades dessas relações parecem cruciais para a possibilidade de mobilização do capital social em benefício de um engajamento político e cívico efetivo.

\section{DESENHO INSTITUCIONAL}

Se, como argumenta Putnam, tanto comunidades cívicas como não-cívicas costumam reforçar-se cada vez mais, fortalecendo suas próprias características, e se esses dois tipos diferentes de equilíbrio têm raízes históricas e culturais, as autoridades públicas não têm muito a fazer para aumentar o estoque de capital social. Ao considerar o Estado um fator meramente exógeno, Putnam "negligencia o papel desempenhado por estruturas políticas e instituições em moldar o contexto da atividade associativa e, logo, da criação de capital social" (MALONEY, SMITH \& STOKER, 2000, p. 803). Uma outra objeção refere-se a uma suposta correlação entre o número de associações e o acesso a informação e a redes sociais, de um lado, e o desempenho governamental, de outro.

Se, como salientam Maloney, Smith e Stoker, "o capital social depende do contexto específico" (idem, p. 804), temos de levar em conta os arranjos institucionais que afetam as relações entre o governo e as organizações da sociedade civil. Sem canais de comunicação que proporcionem às organizações comunitárias condições favoráveis para engajar-se nas questões públicas, o capital social dificilmente pode ser mobilizado em prol da promoção do bem comum. A percepção de Putnam é bastante fatalista na medida em que as raízes históricas e culturais são sobrevalorizadas. Entretanto, as possibilidades governamentais para promover o capital social por meio de "políticas constituidoras" ("constituent policies") (LOWI, 1972), isto é, políticas que visam a modificar as regras do jogo político (BECK, 1993, p. 17), são subestimadas.

Nesse sentido, a análise de Putnam é "demasiadamente centrada na sociedade, subvalorizando agências estatais e outros fatores políticos associados" (LOWNDES \& WILSON, 2001, p. 629). É imprescindível avaliar a relevância do desenho institucional para a relação entre capital social e democracia e o desempenho governamental em geral. As diferenças relativas à democracia e ao desempenho governamental certamente não estão relacionadas apenas às particularidades sociais $\mathrm{e}$ culturais de cada região, como alega Putnam em 
seu estudo sobre a Itália. Pelo menos, o que os recentes estudos sobre experiências brasileiras em democracia local mostram é que inovações concernentes ao desenho institucional fazem de fato a diferença, não apenas para a ampliação da participação política mas também para o fortalecimento da sociedade civil local e, conseqüentemente, a criação de capital social ${ }^{5}$.

As críticas contra a concepção do capital social de Putnam originam-se no institucionalismo que, por sua vez, costuma responsabilizar a fragilidade das instituições como um dos fatores principais para as dificuldades de países em desenvolvimento em consolidar os seus jovens regimes democráticos. Entre os cientistas políticos e administradores é bastante comum a convicção de que a única maneira de "pôr ordem no caos" que supostamente reina nos países em desenvolvimento seria com o auxílio de medidas de "desenho institucional" (PRITTWITZ, 1994, p. 239). Neste sentido, políticas constitutivas ou estruturantes visam não apenas à "manutenção", mas também ao "desenho" e à "renovação" das instituições sócio-políticas (KOOIMAN, 2000, p. 158). Tal compreensão dinâmica de políticas estruturantes está na base de abordagens de construção e desenvolvimento institucional. No passado, essas estratégias foram desenvolvidas e enfaticamente advogadas pelas agências internacio-nais de desenvolvimento, que supunham que tais estratégias contribuiriam para um aumento de governabilidade e de eficiência da "administração do desenvolvimento" nos países do "Terceiro Mundo"6.

As teorias institucionais partem do pressuposto de uma função relacional, reguladora e cultural desempenhada por instituições. Instituições estruturam as relações e redes sociais, regulam a distribuição de gratificações e de posições sociais mediante a definição de metas e a determinação e

\footnotetext{
5 Em relação à importância de desenhos discursivos na política brasileira local, ver Frey (1996; 2002a); em relação ao caso do orçamento participativo e suas consequiências para o desenvolvimento da sociedade civil: Abers (1998a; 1998b) e Santos (1998).

6 Ver Goldsmith (1992) que analisa as abordagens de institution building, desenvolvimento institucional, sustentabilidade institucional e teoria neo-institucionalista em relação a suas contribuições para políticas de desenvolvimento nos países do Terceiro Mundo.
}

destinação de recursos. Sendo as instituições intermediadas por valores, para strong institucionalists como Schelsky (1970), as instituições representam a índole espiritual da sociedade como um todo. Schelsky considera as instituições como positivas, por princípio, por garantirem a estabilidade de sistemas. Conforme essa concepção, o desenvolvimento institucional assume o caráter de um modelo geral de progresso (WASCHKUHN, 1994).

Enquanto a abordagem de Putnam parece demasiadamente centrada na sociedade e demasiadamente fatalista no que diz respeito às possibilidades de engendrar mudanças por meio da ação governamental, a abordagem institucional, ao menos na sua versão mais radical, parece demasiadamente idealista na avaliação dos supostos benefícios do desenvolvimento institucional. As instituições não desempenham apenas o papel de satisfazer necessidades humanas e de estruturar interações sociais. Ao mesmo tempo, as instituições "determinam posições de poder, eliminam possibilidades de ação, abrem chances sociais de liberdade e erguem barreiras para a liberdade individual" (idem, p. 188-189). A institucionalização implica elevados custos em termos de burocratização e de exclusão de muitas vozes (O’DONNELL, 1991, p. 30). Instituições políticas são padrões regularizados de interação, conhecidos, praticados e em geral reconhecidos e aceitos pelos atores sociais, ainda que não necessariamente por eles aprovados. Logo, são produtos de processos políticos de negociação antecedentes, refletem as relações de poder existentes e podem ter efeitos decisivos para o processo político e seus resultados materiais (PRITTWITZ, 1994, p. 239).

Além disso, como supomos, arranjos institucionais influenciam também as condições para a mobilização do capital social. Seria ingênuo ignorar os efeitos das condições legais e constitucionais, das estruturas e procedimentos governamentais e das tradições e práticas da vida política para "moldar" a sociedade civil (LOWNDES \& WILSON, 2001, p. 631). Em contraposição ao institucionalismo tradicional, o neo-institucionalismo "não explica tudo por meio das instituições. Quanto mais consolidado o processo político e quanto mais fragmentadas as instituições, tanto mais o fator institucional tem força explanatória" (BEYME, 1992, p. 76). Especialmente no mundo em desenvolvimento, onde os processos políticos são normalmente mais voláteis e as instituições sujeitas a 
mudanças permanentes, as instituições parecem muito menos decisivas para os processos políticos e seus resultados materiais.

O neo-institucionalismo mantém a rejeição do institucionalismo referente às abordagens de escolha racional e afirma que é imprescindível levar em conta, para além dos interesses pessoais, as instituições e identidades que influenciam o comportamento e as atitudes dos atores políticos nos processos de tomada de decisão. Na prática, os atores políticos estão buscando estratégias apropriadas na base de regras, obrigações, direitos e papéis institucionalizados. Portanto, o pensamento neo-institucionalista defende uma compreensão mais ampla do conceito de instituição: "A idéia central é que a vida é organizada por conjuntos de práticas e significados compartilhados que são considerados dados por um longo tempo. Ações intencionais e calculadas de indivíduos e coletividades são inseridas nessas práticas e significados compartilhados, os quais podem ser chamados de identidades e instituições" (MARCH \& OLSEN, 1994, p. 250).

É exatamente na valorização das práticas e significados compartilhados que convergem a concepção do desenho institucional e a abordagem de Putnam sobre o capital social. No entanto, enquanto para Putnam os lugares preferenciais para o desenvolvimento de tais práticas e significados compartilhados são as organizações cívicas, a vizinhança e a família - nos termos habermasianos podemos denominá-los de esfera do mundo de vida (Lebenswelt) -, os neo-institutionalistas chamam a nossa atenção para as possibilidades de influenciar significados e práticas mediante a ação governamental e o desenho institucional. Segundo March e Simon (1994; 1995) e sua concepção da "governança democrática", a formação e o delineamento da vida política e social torna-se uma das tarefas primordiais de um governo democrático: "A governança democrática é mais do que o gerenciamento da formação de coalizões políticas e de troca política. Envolve também influenciar os processos pelos quais as restrições sobre a troca política são estabelecidas. Os processos pelos quais atores, identidades, significados, recursos, direitos e regras são criados e trocados não são exógenos à governança mas parte central dela" (MARCH \& OLSEN, 1994, p. 264).

Apenas no caso de admitirmos a possibilidade de governos estarem em condições de influenciar o desenvolvimento do capital social, "pode ser possível romper com círculos viciosos "não cívicos' e promover ativamente a 'virtuosa' combinação de engajamento cívico e boa governança" (LOWNDES \& WILSON, 2001, p. 631). Apesar de existirem boas razões para assumir que as possibilidades de influenciar o capital social mediante o desenho institucional podem variar significativamente de acordo com o contexto cultural, a desconsideração do fator institucional - instituições neste caso compreendidas na sua versão mais ampla - parece bastante problemática, até mesmo em regimes consolidados com estruturas formais estáveis.

A opção de influenciar o desenvolvimento do capital social por meio de intervenções governamentais envolve, certamente, também riscos no que tange à autonomia da sociedade civil, especialmente em uma sociedade como a brasileira, caracterizada por uma tradição de atitudes e estruturas governamentais clientelistas e paternalistas. A mera existência de organizações cívicas ainda não diz nada a respeito do grau de autonomia dessas organizações ou da sua dependência de instituições governamentais.

O exemplo brasileiro apresenta uma situação bastante difusa e variada de inter-relações estabelecidas entre as organizações cívicas e as instituições governamentais, como mostram os seguintes três exemplos. Em primeiro lugar, podemos mencionar uma situação bastante comum nas cidades brasileiras: organizações tradicionais de moradores que dependem de práticas clientelistas e buscam fazer valer os seus interesses muitas vezes às custas de outras organizações similares. Tais associações, freqüentemente, mostram-se incapazes de engajarem-se em atividades que exigem a colaboração com outras organizações semelhantes e, por outro lado, mostram-se bastante efetivas em obter recursos públicos por intermédio de vereadores. De fato, para os vereadores a atuação enquanto mediadores entre a administração pública e as organizações comunitárias locais é uma das fontes decisivas de legitimidade política.

Podemos encontrar uma outra situação peculiar nas favelas do Rio de Janeiro ou nas favelas de outras grandes cidades brasileiras, onde a vida social é dominada pelo crime organizado e onde a regulação por meio da ação governamental é deficiente ou inexistente. Nesses lugares encontramos formas consolidadas de interação social baseadas 
na condição de pobreza e na disseminação do medo, mas que ao mesmo tempo não deixam de oferecer estrutura e um certo grau de estabilidade à convivência social. Nesse contexto de grandes zonas de moradia popular abandonadas pelo Estado, a aceitação da ordem estabelecida pelo crime organizado representa, na verdade, a única fonte - apesar de precária - de segurança social e a única possibilidade de sobrevivência em uma ambiente progressivamente ameaçador e funesto.

Por fim, existem no Brasil também experiências democráticas interessantes em que governos locais, comprometidos com a democratização do sistema político, procuraram reinventar as relações políticas por meio de inovações políticas institucionais, como, por exemplo, por meio do orçamento participativo. Tais inovações evidenciam um potencial elevado de solidariedade e aprendizagem institucional em casos de governos dispostos a estabelecer processos públicos de participação e deliberação política (FREY, 2002a).

Essa variedade de situações demonstra que tanto o fator institucional, a variável "capital social" como também o contexto cultural específico são todos elementos cruciais que devem ser levados em consideração para entender as potencialidades de mudança inerentes no nível comunitário. Portanto, é fundamental direcionar a nossa atenção para a interface entre as instituições governamentais e o capital social. Do mesmo modo como o capital financeiro pode ser desperdiçado e simplesmente mantido fora de circulação, do mesmo modo como propriedades de terra podem ser improdutivas, também o capital social pode estar inativo, ou até prejudicial e contraproducente se não for conduzido de maneira a fomentar o bem comum. Mas como será possível estimular o capital social de modo que o bem comum possa ser fortalecido?

Na seção seguinte, procuraremos evidenciar o potencial da abordagem de rede para proporcionar um referencial para um melhor entendimento dos processos de desenvolvimento do capital social e das possibilidades de influenciar de modo positivo o capital social em prol do desenvolvimento comunitário e do fortalecimento do bem comum.

\section{REDES SOCIAIS}

Conforme já mencionamos na "Introdução", os processos dominantes na sociedade moderna, segundo Castells, estão crescentemente organi- zados em torno de redes: "As redes constituem a nova morfologia social de nossas sociedades, e a difusão da lógica de redes modifica de maneira substancial a operação e os resultados dos processos produtivos e de experiência, poder e cultura" (CASTELLS, 1999, p. 497). O novo paradigma das tecnologias da informação é considerado por Manuell Castells como a base material para a expansão penetrante de redes em toda a estrutura social da sociedade moderna. Apesar de as redes poderem ser consideradas formas antigas de convivência humana, "elas tomaram uma nova forma, nos tempos atuais, ao transformarem-se em redes informacionais, revigoradas pela internet" (CASTELLS, 2001, p. 1).

Todavia, as tendências gerais do ciberespaço tendem a reforçar os já bem conhecidos processos de exclusão e de aumento de concentração de poder, tanto no âmbito econômico quanto político (CASTELLS, 1996; SASSEN, 1997). Em primeiro lugar, as TICs provocam tendências de segmentação e exclusão dentro do próprio ciberespaço. As novas redes não apenas distribuem poder, mas elas tornam possível a disseminação de novas e diferentes formas de poder. Uma das importantes manifestações de tais cibersegmentações é a proliferação das intranets privadas que são fortalezas excessivamente vigiadas e isoladas da internet aberta (SASSEN, 1997, p. 228). Mas essas tendências de exclusão e concentração de poder não são exclusividade do ciberespaço, mas tendem a determinar a vida social, política, cultural e econômica no espaço real.

Na sua teoria do "espaço de fluxos", Manuel Castells salienta não apenas as dimensões econômica e política, mas também as dimensões culturais desses processos de segmentação, baseados em estruturas sócio-técnicas. Sua interpretação da dinâmica social da sociedade em rede revela interessantes percepções sobre transformações sociais induzidas pelas TICs. Como resultado, podese chegar a um melhor entendimento das perspectivas de redes comunitárias e as possibilidades do uso das TICs em prol do desenvolvimento sustentável de comunidades locais.

De acordo com Castells, a articulação espacial das funções dominantes na sociedade em rede acontece dentro de redes de interação viabilizada pela utilização de equipamentos de telecomunicação. A infra-estrutura pode ser vista como expressão dessa rede de fluxos, cuja arquitetura e 
conteúdo são determinados pelas formas existentes de poder (CASTELLS, 1999, p. 437). Isto é, a base material desse espaço de fluxos é proporcionada pela criação de infra-estrutura de telecomunicação, que tende a excluir grandes segmentos sociais dos benefícios da sociedade de informação.

No que diz respeito à organização social espacial, Castells argumenta que a sociedade informacional é organizada de uma forma assimétrica em torno dos interesses dominantes da elite econômica: "A forma fundamental de dominação de nossa sociedade baseia-se na capacidade organizacional da elite dominante que segue de mãos dadas com sua capacidade de desorganizar os grupos da sociedade que, embora constituam maioria numérica, vêem (se é que vêem) seus interesses parcialmente representados apenas dentro da estrutura do atendimento dos interesses dominantes. A articulação das elites e a segmentação e desorganização da massa parecem ser os mecanismos gêmeos de dominação social em nossas sociedades" (idem, p. 440).

Consequiência dessa tendência é um crescente afastamento do mundo do big business e da política organizada - onde ocorre a acumulação de poder e de riqueza e cujo espaço de referência é o mundo como um todo - das comunidades locais, cujas experiências são criadas localmente e baseadas na história e na suas culturas específicas. O poder global segue cada vez mais uma lógica peculiar, esquivando-se das críticas das sociedades nacionais e, mais ainda, das comunidades locais. Essa rede global de dominação garante sua exclusividade não por meio da obstrução explícita do acesso, mas pelo desenvolvimento de regras e códigos culturais específicos, cuja posse abre o acesso a essas estruturas e redes de poder.

Isso significa que, de um lado, é preciso conservar as instituições democráticas a fim de poder manter as aparências democráticas; de outro lado, são erguidas barreiras culturais para evitar a entrada de representantes políticos nos mais altos círculos do poder onde são tomadas as decisões estratégicas. De fato, as principais decisões são tomadas em microrredes pessoais, em comunidades simbolicamente segregadas que representam subculturas de pessoas interconectadas, ligadas a localidades comuns. Essas comunidades privadas representam os pontos nodais nesse espaço de fluxos, onde preocupações e interesses privados são discutidos em círculos fechados e, subseqüentemente, projetados para as macrorredes, sustentadas, por sua vez, pelas tecnologias de telecomunicação.

Um segundo elemento mencionado por Castells, que contribui para a distinção cultural de elites na sociedade da informação, está relacionado à criação de um estilo de vida peculiar que dá homogeneidade à elite informacional e transcende as fronteiras culturais tradicionais de sociedades nacionais. Em consequiência, ocorre uma certa uniformização do ambiente simbólico das elites no mundo todo, substituindo as particularidades, historicamente condicionadas, de cada localidade.

A interpretação de Castells da sociedade em rede e das estratégias e mecanismos utilizados pela elite empresarial da nova economia informacional é bastante reveladora, especialmente se vista em contraste com os processos de fragmentação e segmentação que podemos observar no âmbito da sociedade civil, sobretudo em nível comunitário. "Segue uma esquizofrenia estrutural entre duas lógicas espaciais que ameaça romper os canais de comunicação da sociedade. A tendência predominante é para um horizonte de espaço de fluxos a-histórico em rede, visando a impor sua lógica nos lugares segmentados e espalhados, cada vez menos relacionados uns com os outros, cada vez menos capazes de compartilhar códigos culturais" (idem, p. 451-452).

Entretanto, não se trata apenas de (re)construir as pontes culturais e físicas entre essas duas formas de espaço, como sugere Castells, mas também de criar redes similares em nível comunitário com o objetivo de promover identidade, solidariedade e novas formas de cooperação e interação em conformidade com as particularidades da sociedade informacional.

Mas o que são essas características particulares que diferenciam redes de outros tipos de coordenação social, sobretudo o mercado e as organizações? Os mercados são coordenados por mecanismos de preço, de uma forma específica e espontânea; as organizações, por meio de regras formais, de uma forma não-específica e baseadas em regulamentos; já as redes são normalmente coordenadas por meio de discurso fomentando relações de confiança mútua.

Em relações de mercado os atores costumam ser independentes. O contrário ocorre nas orga- 
nizações hierárquicas em que os atores são dependentes, ao passo que em redes é imprescindível a ocorrência de formas de cooperação entre seus membros, viabilizadas e sustentadas por relações de interdependência. $\mathrm{O}$ acesso aos mercados é aberto, pelo menos para aqueles com poder aquisitivo. No caso de organizações o acesso é regulamentado por normas, enquanto em redes o acesso é restrito aos seus membros, excluindo os nãomembros. O horizonte de tempo, nas relações de mercado, é de curto prazo; em organizações, de longo prazo; em redes, finalmente, de médio prazo. $\mathrm{O}$ último critério refere-se à maneira como conflitos são resolvidos. No caso de relações de mercado, a arbitragem é garantida por lei; nas organizações, pela distribuição de poder; em redes, os conflitos são decididos via negociação (WEYER, 2000, p. 5-10).

Alega-se que as redes são capazes de proporcionar resultados que normalmente só o mercado ou as hierarquias são capazes de produzir, apresentando porém vantagens adicionais. Em redes pode ocorrer todo tipo de troca sem os seus membros serem expostos às incertezas e riscos das transações de mercado. As redes facilitam um comportamento coordenado, sem a necessidade de aceitar a rigidez de organizações inflexíveis e burocráticas. A rede mostra-se como a única estrutura de ação capaz de cumprir duas funções básicas: primeiro, a função estratégica de reduzir as incertezas com relação ao comportamento de outros atores, como competidores ou parceiros; segundo, a função instrumental de melhoria do desempenho, isto é, um aumento dos resultados produzidos. Além disso, as redes parecem preservar a autonomia dos parceiros e aumentar sua capacidade de aprendizagem.

Nesse sentido, as redes sociais podem ser compreendidas como formas independentes de coordenação de interações. A marca central da rede é a cooperação, baseada em confiança entre atores autônomos e interdependentes. Estes trabalham em conjunto por um período limitado de tempo e levam em consideração os interesses dos parceiros envolvidos, que estão conscientes de que essa forma de coordenação é o melhor caminho de alcançar seus objetivos particulares. É em função dessa capacidade de agregação que as redes têm um grande potencial para instigar processos de aprendizagem e são defendidas para a implementação de projetos de inovação, nos casos em que os riscos envolvidos apresentarem-se altos demais para cada um dos parceiros individualmente (idem, p. 11).

Essas qualidades da estrutura de rede é que tornam a opção comunitária tão atraente para a política local. No entanto, resultados positivos só podem ser esperados se as comunidades locais conseguirem colocar em prática o modelo de interação social da colaboração em rede. Infelizmente, como Castells argumenta, as condições gerais não são muito favoráveis para os processos de inovação social impulsionados de baixo para cima.

Dado o fato de que as mais importantes decisões que afetam as comunidades locais são tomadas em espaços privados ou em redes globais por elites empresariais, sem um envolvimento político das populações locais, as comunidades em todo o mundo estão crescentemente expostas a uma incerteza geral. Esse aumento das incertezas não tem apenas a ver com o "sistema da irresponsabilidade organizada" que, de acordo com Ulrich Beck (1988, p. 104), caracteriza a sociedade de risco, levando a um "fatalismo industrial" e a uma aceitação e um conformismo generalizados concernentes aos riscos industriais. Além disso, parece que foi estabelecido, em função dos recentes processos de desregulação e privatização, um sistema organizado de incerteza social, baseado na disseminação de insegurança e na ausência de garantias (BAUMAN, 2000, p. 14). Essa estratégia de criação de incerteza, conscientemente promovida, resulta em medo e aflição que fomenta atitudes individualistas de sobrevivência, mina tentativas de ação coletiva e enfraquece os laços sociais que normalmente mantêm as comunidades unidas. Ambas as tendências favorecem o conformismo e a apatia política, impedindo a mobilização das comunidades com o objetivo de reduzir as incertezas.

Para Beck (1993) e Bauman (2000), uma possível solução para esse dilema passa necessariamente pela politização como único caminho possível para superar o cinismo e o conformismo que costumam estrangular os últimos canais de comunicação existentes entre as esferas privada e pública.

Enquanto, conforme a interpretação de Castells, a elite informacional costuma discutir seus interesses e preocupações em círculos privados de negociação e tem à sua disposição meios para colocar em prática as suas resoluções, a grande massa carece de tais espaços públicos/privados onde seus problemas particulares poderiam ser 
discutidos e tornados públicos. Conforme Bauman, "a chance para mudar isso depende da ágora - esse espaço nem privado nem público, porém, mais precisamente, público e privado ao mesmo tempo. Espaço em que os problemas particulares encontram-se de modo significativo - isto é, não apenas para extrair prazeres narcisísticos ou buscar alguma terapia por meio da exibição pública, mas para procurar coletivamente alavancas controladas e poderosas o bastante para tirar os indivíduos da miséria sofrida em particular; espaço em que as idéias podem nascer e tomar forma como 'bem público', 'sociedade justa' ou 'valores partilhados"” (idem, p. 11).

$\mathrm{Na}$ sociedade contemporânea, a opção comunitária está confrontada com dois desafios principais, ambos em aparente conflito: em primeiro lugar, trata-se de aprender com a elite empresarial no que diz respeito à sua estratégia de organizar-se em redes e aumentar, desse modo, a capacidade para a ação coletiva e a cooperação por meio da promoção de confiança e reciprocidade entre os membros das redes; em segundo lugar, trata-se de evitar as tendências de exclusão-muito comuns nas redes empresariais - e garantir procedimentos democráticos e práticas coletivas baseadas em deliberações públicas e interativas, de modo que condições para a promoção do bem comum possam ser efetivamente melhoradas. No contexto de crescentes conflitos sociais e culturais, em uma sociedade cada vez mais complexa e diversificada, e em face de novas e inusitadas potencialidades de criação de redes em função da disseminação dos TICs, os riscos relacionados à segregação, à exclusão e a um possível aumento de conflitos e de intolerância devido à proliferação dessas novas estruturas de rede não devem ser subestimados.

No que tange às redes comunitárias, é importante reconhecer as novas potencialidades que a internet proporciona para fomentar estruturas de rede no âmbito da vizinhança e de cidades e, dessa maneira, fortalecer comunidades locais e melhorar as condições de vida locais 7 . No entanto, simultaneamente, torna-se crucial estar ciente dos riscos que tais estratégias acarretam para a sociedade como um todo quando as exigências demo-

7 Relativamente à experiência da cidade de Bolonha, ver Guidi (2002); para a de Amsterdã, ver Castells (2001, p. 146-155); para as de outras cidades européias, Frey (2002b). cráticas são ignoradas ou negligenciadas. A opção comunitária tem que levar em consideração as condições institucionais, as relações de poder locais e a necessidade de um grande esforço no que concerne à revitalização da democracia local e de base.

Uma das principais exigências refere-se à ampliação dos espaços públicos para a deliberação pública e esforços de incluir amplas partes da população em processos de tomada de decisão políticas e sociais, já que no Brasil a política sempre foi uma questão de uma elite social e política muito pequena.

Tomando as formas de coordenação mencionadas acima como referencial analítico, podemos tentar enquadrar as relações sociais e políticas nessa tipologia proposta. Curiosamente, podemos constatar que no Brasil os processos sociais parecem bem mais alinhados com o modelo de rede do que com o mercado ou o modelo organizacional de coordenação social. De fato, a lógica do mercado costuma contrastar fortemente com as redes de interesse que determinam as relações sociais no Brasil e que, freqüentemente, baseiam-se em laços familiares ou de amizade. Em geral, esses tipos de redes operam em prol da anulação das leis do livre mercado. Correspondentemente, as regras e normas, que, em acordo com o modelo hierárquico, definem o acesso a organizações, são também habitualmente anuladas por essas dominantes forças sociais. Podemos dizer que as tradicionais redes sociais minam as funções originais dos mercados e organizações burocráticas. Sendo assim, elas podem ser interpretadas como elementos fundamentais dentro de um modelo de dominação em que uma pequena e poderosa elite explora as vantagens das relações em rede, em seu próprio interesse e em detrimento dos excluídos dessas redes.

As redes sociais que existem no nível da vizinhança e das comunidades locais, especialmente em comunidades pobres, são igualmente baseadas em laços familiares ou de amizade, mas em geral têm pouco a opor a essas redes dominantes. Nesse âmbito, podemos distinguir dois tipos de redes locais. Em primeiro lugar, observam-se redes sociais nascidas das necessidades materiais. Nesse caso, a cooperação é resultado de estratégias de sobrevivência pessoal e o objetivo primordial é tentar evitar ou restringir a degradação social. Muitas vezes tais redes dependem de sua capacidade de estabelecer relações efetivas com as elites dominan- 
tes nas administrações locais, em geral caracterizadas por estruturas paternalistas e clientelistas. Em segundo lugar, ganham espaço novas redes sociais que surgem como novos focos de concentração de poder, muitas vezes relacionados ao crime organizado e ao tráfico de drogas. Esses tipos de redes representam uma ameaça à elite tradicional. Como conseqüência, alianças entre redes do crime organizado e do tráfico de drogas, de um lado, e redes das elites políticas e sociais tradicionais, de outro, são traços cada vez mais comuns do atual modelo de dominação social.

Até aqui é possível constatar que redes dificilmente representam uma panacéia para os problemas que as comunidades locais estão enfrentando nos países em desenvolvimento. Como mostra o caso brasileiro, elas podem sustentar e perpetuar um sistema de dominação e de controle incompatível com os princípios da democracia e da participação política. As reflexões sobre redes comunitárias demonstram que é preciso ficar atento para o fato de que uma concepção aparentemente democrática pode facilmente ser transformada em uma ferramenta capaz de reforçar as relações de poder existentes, sobretudo se não houver esforços explícitos para superar impedimentos institucionais e culturais.

Como alega Castells, a concepção de rede é diretamente relacionada ao novo paradigma das tecnologias de informação. Da perspectiva brasileira, essa constatação tem que ser relativizada. Uma influência forte de atitudes e padrões pré-modernos, em um contexto de uma sociedade industrial moderna, pode também apoiar estruturas de rede. No entanto, de acordo com a argumentação de Castells, a localidade e a proximidade física perdem sua importância para sustentar redes sociais em função da disseminação da internet. Enquanto Castells frisa a ambivalência dessa transformação paradigmática, existem outros autores com visão muito mais otimista, alegando um efeito democratizante geral dessas novas tecnologias. A seção seguinte apresenta esse debate bastante controverso, no intuito de ajudar a reflexão acerca das possibilidades de uso dessas novas tecnologias como instrumentos fomentadores e sustentadores das redes sociais em uma perspectiva democrática e emancipatória.

\section{REDES COMUNITÁRIAS E TECNOLOGIAS DA INFORMAÇÃO E COMUNICAÇÃO}

Defensores do novo mundo virtual estão con- vencidos de que na nova sociedade da informação as redes globais de infra-estrutura de comunicação, exploradas por atores privados, serão instrumentos decisivos para a promoção da democracia, do desenvolvimento e da solidariedade, bem como para solucionar as grandes desigualdades sociais em nosso planeta (SFEZ, 2000, p. 51). Castells acredita "que a internet é um instrumento fundamental para o desenvolvimento do Terceiro Mundo" (CASTELLS, 2001, p. 5). E, de fato, enquanto as instituições territoriais tradicionais são mais hierárquicas e rígidas, a internet tende a privilegiar modos de relacionamento transversais e estruturas mais fluidas, em maior sintonia com as estruturas de redes, que caracterizam os processos sociais e políticos nas sociedades democráticas modernas. Sendo assim, deve-se esperar efeitos significativos dessas redes de telecomunicação não apenas no âmbito do big business, mas também nos âmbitos da sociedade, da cultura e das instituições políticas (POSTER, 1997, p. 215). De acordo com Wellman, na sociedade em rede, "fronteiras são permeáveis, interações acontecem com diversos outros, conexões mudam entre múltiplas redes e hierarquias podem ser reduzidas e recursivas" (WELLMAN, 2001, p. 227).

Não há dúvidas de que as redes eletrônicas transformam as dimensões de tempo e espaço. A informação é transmitida em tempo real e pode-se estabelecer contatos imediatamente, independentemente da distância espacial. A comunicação em rede garante, em princípio, um acesso universal, confortável, não-filtrado e de baixo custo a informações e processos políticos. Entretanto, o potencial democrático específico da internet baseia-se em sua estrutura não-hierárquica e cibernética que, em princípio, favorece a interatividade.

Um outro possível efeito democratizante consiste na expectativa de que os fatores idade, sexo, cor ou raça perdem relativamente importância no ciberespaço, uma vez que "a entrada dos atores na internet não depende de uma situação pré-estabelecida, mas apenas da sua ação no presente momento" (SFEZ, 2000, p. 52). Finalmente, existem expectativas de que cidadãos que normalmente são mais relutantes em engajar-se em debates públicos poderiam acabar envolvendose mais diretamente em processos de deliberação e tomada de decisão política, visto que a comunicação pelo correio eletrônico reduz os riscos da exposição pessoal que caracteriza tanto a comunicação face-a-face quanto debates em arenas públi- 
cas (GRAHAM, 1999, p. 68). Portanto, parece que a relevância democrática da internet relacionase, antes de qualquer coisa, ao seu potencial para promover uma comunicação direta, descentralizada e interativa entre o poder político e o eleitorado.

Além disso, proporcionam-se novas possibilidades para processos informais de deliberação política (DAHLBERG, 2001, p. 1). A comunicação de mão dupla, que se torna possível na internet, contrapõe-se à comunicação de mão única, que prevalece nos meios de comunicação de massa. Enquanto, por exemplo, na televisão os debates públicos são conduzidos em geral pelos líderes de opinião, sem uma participação ativa dos cidadãos comuns, surgem com a internet novas possibilidades de criação de uma esfera pública interativa, um tipo de "ágora eletrônica", sobretudo devido à vantagem da dissolução do espaço enquanto condição de comunicação (ROESLER, 1997, p. 182).

Da perspectiva das comunidades locais, as TICs representam um possível novo canal por que as comunidades podem expressar as suas demandas e expectativas, por que cidadãos podem ser envolvidos em processos de tomada de decisão política e, finalmente, por que uma esfera pública local pode ser sustentada e a democracia local fortalecida ${ }^{8}$. Neste artigo estamos enfocando não apenas as relações entre cidadão e governo, mas também as potencialidades comunicativas entre os próprios cidadãos, e com isso as possibilidades de fazer uso das TICs em prol do desenvolvimento comunitário e da mobilização do capital social.

No entanto, antes de abordar a possível contribuição das TICs para o fortalecimento das comunidades locais, é preciso refletir sobre as características de comunidades e as implicações dos processos de segmentação e fragmentação para a sua mobilização. Abordagens teóricas sobre relações sociais comunitárias mencionam, em geral, seis propriedades de comunidades, elencadas a seguir. Diferencia-se entre as variáveis estruturais, que são: 1) laços sociais densos e fortes; 2) envolvimento e integração social proporcionado por meio de instituições comuns; 3 ) eventos rituais; 4) grupos de tamanho reduzido; e

8 Partindo do referencial teórico da esfera pública e da democracia deliberativa eu abordei essa questão em dois outros trabalhos recentes (FREY, 2001a; 2001b); ver também Coleman e Gotze (2002). as variáveis culturais que são 5) percepções de similaridade com as características físicas, o estilo particular, a forma de vida, ou as experiências históricas dos outros e 6) crenças comuns em relação a um sistema compartilhado de idéias, uma ordem moral, uma instituição ou um grupo (BRINT, 2001, p. 3-4).

O que mostram estudos empíricos sobre comunidades é que freqüentemente "comunidades não parecem muito com comunidades. Elas são tanto penetradas por interesses, poder e divisões quanto mercados, corporações ou governos municipais" (idem, p. 6). Na prática, os contatos entre membros de comunidades não são necessariamente mais intensos do que com pessoas de fora da comunidade. Muitas vezes comunidades caracterizam-se por estratificação social e as decisões relevantes são tomadas pelo grupo de status dominante. Nem são as comunidades, necessariamente, baseadas em quaisquer laços sociais sobremaneira intensos ou altamente focalizados. Devido a uma crescente contestação da "imagem de relações comunitárias calorosas e de apoio recíproco" (ibidem) por parte de estudos empíricos, ganha cada vez mais atenção o referencial de redes sociais. Wellman "define 'comunidade' como redes de laços interpessoais que proporcionam sociabilidade, apoio, informação, um senso de pertencimento e identidade social" (WELLMAN, 2001, p. 228).

Ao contrário das definições tradicionais de comunidade, a idéia da comunidade enquanto rede frisa mais as vantagens em termos de benefícios práticos e materiais conferidos aos membros de tais redes, e menos à idéia de crenças comuns e de uma ordem moral unificadora ou até de um tipo de "vontade natural" inerente às comunidades. Uma contribuição importante para essa discussão vem dos estudos sobre comunidades eletivas. De acordo com Brint, comunidades de escolha são baseadas em interesses comuns e apoio mútuo. As interações entre os seus membros mostramse em geral bem mais intensas e efetivas do que aquelas em comunidades que são definidas exclusivamente pela propinqüidade física.

Brint identifica diversas razões para a tendência das Ciências Sociais em privilegiar as redes sociais em detrimento da abordagem da comunidade. Primeiro, parece que as formas mais estáveis de comunidades territorialmente delimitadas tendem a desaparecer gradualmente na sociedade moderna. 
Segundo, observa-se um avanço da escolha racional como pensamento predominante nas últimas décadas. Finalmente, ele menciona o fato de que os próprios cientistas sociais e os profissionais altamente qualificados vivem em um mundo em que as interações de curto prazo e a pluralidade de contatos sociais são valorizados e vistos como fatores fundamentais para o sucesso social e econômico. Essa percepção pode, no entanto, basear-se em uma apreensão equivocada, especialmente se vista da perspectiva de comunidades pobres e da necessidade de superar situações de risco social. Segundo Brint: "A tendência atual de focalizar rituais de interações de curto prazo relacionados a estruturas de redes sociais corre o risco de distorcer (e apagar) a realidade daquelas estruturas de tipo Gemeinschaft que continuam existindo" (BRINT, 2001, p. 8). Sobretudo no contexto de países em desenvolvimento com sistemas de segurança social extremamente precários, as comunidades locais continuam desempenhando um papel importante na luta diária das pessoas pela sua sobrevivência.

$\mathrm{Na}$ sua conclusão, Brint constata que os mecanismos integradores de comunidades são fortemente relacionados a interações face-a-face e a processos de monitoramento visando a alcançar a conformidade, ao passo que "um ambiente de iguais autônomos, comprometidos com um conjunto de normas morais comuns, só é possível em um mundo em que membros estão raramente, ou nunca, co-presentes" (idem, p. 20)

São exatamente essas as condições que podem ser observadas em comunidades virtuais de interesse, em que os membros dificilmente se encontram e as interações costumam limitar-se àqueles tópicos específicos que motivaram a criação da comunidade (BLANCHARD \& HORAN, 1998, p. 295).

Brint tem a expectativa de que esses tipos de grupos, baseados em atividades comuns e conectados de modo menos firme e permanente - uma característica cada vez mais dominante nas organizações sociais das sociedades industriais contemporâneas - levam "algumas das virtudes de comunidades para o mundo moderno, evitando ao mesmo tempo seus vícios característicos e suas conotações puramente místicas" (BRINT, 2001, p. 20). Assim, a comunidade de escolha surge como uma forma de organização promissora para o dinamismo da vida social no mundo contem- porâneo, capaz de criar condições para as pessoas atuarem na busca de seus interesses coletivos, sem permanecerem presos a um cânone de normas éticas e morais das comunidades tradicionais.

Existe, no entanto, o perigo de "que 'comunidades virtuais' e comunidades particulares de interesse - enquanto elas ganham sua grande força da sua capacidade de criar conexões - podem ser também excludentes e elitistas" (OAKLEY, 2001, p. 3). Essa argumentação torna-se ainda mais convincente face à tendência de tais grupos de correligionários de discutir apenas seus interesses específicos, fortalecendo, dessa maneira, as opiniões e convicções existentes no grupo e ignorando a pluralidade de tópicos e opiniões que existem em sociedade. Isso se torna mais evidente no que Robert Bellah chama de "lifestyle enclaves", as quais celebram o 'narcisismo da similaridade' por meio do estilo de vida comum de seus membros" (DOHENY-FARINA, 1996, p. 50). Teme-se que as novas oportunidades para a formação de comunidades, guiadas exclusivamente por interesses, possam fortalecer a intolerância e o consumismo, além de fomentar a retirada da esfera pública, o desencantamento com a política e até mesmo a proliferação do fundamentalismo.

Tendo à nossa disposição novas tecnologias para selecionar aquelas informações que queremos acessar e para escolher as pessoas com quem queremos comunicar-nos, nossa percepção da realidade tende a limitar-se cada vez mais. Nós poderemos sentir-nos confortáveis e bem entendidos estando entre os membros de nosso grupo de escolha, porém inseguros e ameaçados fora dele. Como a sociedade depende de um tipo de solidariedade que transcende o engajamento em favor dos correligionários, a opção comunitária pode entrar em oposição com a própria idéia de sociedade, reduzindo a comunicação e a compreensão entre grupos em sociedades cada vez mais marcadas pela diferença.

Comunidades virtuais podem contribuir para cultivar uma outra tendência crítica: na medida em que os temas eletivos determinam cada vez mais a atenção das pessoas e podem ser amplamente satisfeitos devido às novas tecnologias, $o$ interesse e a disposição de engajar-se em favor das comunidades locais reais pode diminuir. Como sugerimos anteriormente, comunidades locais reais continuam desempenhando um papel importante, especialmente em condições locais de risco social. 
Do ponto de vista de países em desenvolvimento surgem com isso algumas questões cruciais: podemos realmente esperar que comunidades com poucas possibilidades efetivas de interação possam contribuir para a melhoria das condições de vida no nível da vizinhança? Será que elas reforçam ainda mais a tendência das pessoas a preocuparem-se cada vez mais com seus interesses individuais e cada vez menos com o ambiente físico e com seus vizinhos, que residem ao lado? Existem possibilidades de fazer as vantagens de comunidades virtuais de interesse trabalhar em favor da intensificação de interações sociais e da cooperação entre comunidades reais? Como comunidades on-line deveriam ser organizadas e estruturadas para fortalecer, simultaneamente, relações de longa distância e laços sociais locais (HORRIGAN, 2001)? E, finalmente, qual deveria ser o papel desempenhado pelas agências governamentais na criação e promoção de comunidades interativas locais?

As experiências com a criação de redes cívicas locais, apoiados em aplicativos de internet, mostram a importância da ação governamental em projetos de democracia eletrônica local que visam fortalecer tais redes dentro de uma perspectiva emancipatória e democrática (CASTELLS, 2001; FREY, 2002b). Em todas as cidades engajadas na criação de redes cívicas observa-se uma preocupação grande em relação a como promover um ambiente mais interativo nas comunidades locais.

Em boa parte dos casos analisados, considerou-se a tecnologia uma ferramenta, de um lado, para a criação de uma administração mais eficiente e melhor adaptada às necessidades dos usuários de serviços públicos e, de outro lado, para o fortalecimento das comunidades locais, o aumento da solidariedade e a ampliação dos laços sociais e da participação política nos processos locais de tomada de decisão.

Para alcançar esses objetivos "macro" as iniciativas governamentais concentram-se em quatro campos de ação preferenciais: 1) criação de pontos de acesso público à internet; 2) campanhas de alfabetização digital; 3) apoio a comunidades virtuais locais e 4) fortalecimento de redes "reais" de vizinhança por meio do uso das TICs.

As experiências européias sugerem que a internet e outras tecnologias informacionais providenciam ferramentas promissoras para o fortalecimento das comunidades locais e dos laços sociais e para a experimentação com o exercício da cidadania e o aperfeiçoamento de processos de democracia local. Mas mesmo nas cidades mais avançadas estamos ainda distantes de uma situação em que a nova interconectividade da internet possa promover novos padrões de tomada de decisão política e uma transformação substancial no tocante às desigualdades sociais.

\section{CONSIDERAÇÕES FINAIS}

A sociedade civil global está organizando-se para preparar propostas para a Conferência Global sobre a Sociedade da Informação, que se realizará em Genebra (2003) e Túnis (2005)9 ${ }^{9}$ O movimento das redes cívicas adquiriu uma dimensão igualmente global, visando a renovar a vida social e democrática na sociedade da informação contemporânea a partir do âmbito local ${ }^{10}$. No nível local, o número de iniciativas governamentais e não-governamentais, experimentando novas formas de participação via internet, está aumentando constantemente. Apesar da tendência dominante de um ciberespaço crescentemente privatizado e comercializado e de um desenvolvimento do setor de telecomunicação marcado pela lógica do mercado e do lucro rápido, todas essas iniciativas dãonos motivos para crer que o ciberespaço possa operar "como um bem comum, [...] como um espaço de acesso público em que cidadãos criam e compartilham bens públicos livres" (LEVINE, 2002, p. 13) e como um espaço de experimentação democrática capaz de sustentar práticas democráticas em geral.

Se, como salienta Castells, "o Estado na era da informação é um Estado organizado em redes, um Estado composto de um complexo web de instituições internacionais, multinacionais, nacionais, regionais, locais e não-governamentais, ne-

\footnotetext{
9 Mais informações sobre a plataforma da sociedade civil estão disponíveis no seguinte sítio: http:// www.geneva2003.org.

10 O movimento global de redes cívicas organizou diversos congressos nos últimos anos: o primeiro em Barcelona, em 2000; o segundo em Buenos Aires, em 2001 (http:// www.globalcn2001.org) e o último congresso em Montreal, em outubro de 2002 (http://www.globalcn2002.org). O movimento GlobalCN Partnership mantém uma plataforma de cooperação no sítio http://www.globalcn.org.
} 
gociando a partilha de poder e a tomada de decisão" (CASTELLS, 2000, p. 14), então os cidadãos e os agentes sociais precisam estar preparados e treinados para essas novas práticas de coordenação social e de tomada de decisão. Iniciativas como redes cívicas, fóruns de discussão e sistemas de mediação on line são fundamentais para preparar as instituições e organizações para essas novas formas de uma "governança social negociada" (HIRST, 2000, p. 19), além de treinar os cidadãos na arte de conversação, negociação, argumentação e deliberação.

Enquanto as democracias representativas liberais parecem funcionar melhor no contexto de uma civic culture, em que o cidadão não é necessariamente racional e ativo, mas "pode combinar algum grau de competência, envolvimento e atividade com passividade e não envolvimento" (ALMOND \& VERBA, 1963, p. 487), dando apoio a um modelo elitista de tomada de decisão política, a emergente sociedade em rede mostra-se bem mais severa: ou faz-se parte da rede e habilita-se a explorar as oportunidades que as novas tecnologias e as redes sociais oferecem, ou está-se condenado a ficar à margem dos processos sociais e políticos. A primeira concepção é mais alinhada com o modelo do Welfare State, em que um Estado relativamente forte com suas instituições políticas e administrativas assume responsabilidade social para proporcionar os serviços públicos e arbitrar em conflitos sociais. O segundo modelo é mais alinhado com o modelo neoliberal de um Estado mínimo em um mundo interdependente e globalizado, que cada vez menos dispõe dos meios e mecanismos necessários para responder às crescentes demandas sociais.

Esse novo contexto social, político e econômico exige novas abordagens e padrões políticos de ação estatal. Uma possibilidade seria tentar reverter as recentes tendências de liberalização e globalização, buscando reforçar o modelo do Estado do Bem-estar Social e da ação estatal centralizada e, no campo político, tentar revigorar as democracias liberais, baseadas em partidos políticos fortes, e os meios de comunicação de massa. Entretanto, tendo em vista a globalização e a diversificação social e cultural, essa opção tornase cada vez menos realista. A segunda possibilidade consiste na perseguição de um modelo de um "empowering State" (WRIGHT, 1996, p. 15), engajado em preparar o cidadão para que este possa tomar o seu destino em suas próprias mãos. A promoção de redes cívicas pode ser considerada uma opção importante dentro dessa abordagem de ação estatal. Face à incapacidade das autoridades estatais em providenciar os produtos e serviços sociais necessários, a concepção de um Estado facilitador e estimulador de inovação social e mediador de conflitos sociais não é apenas uma opção mais realista. Sendo o foco da atenção concentrado no indivíduo e no desenvolvimento de suas capacidades pessoais, assim como na melhoria das condições para ação coletiva, por meio do fortalecimento de movimentos sociais e organizações não-governamentais, a concepção tem um forte viés emancipatório, tornando os cidadãos mais autônomos frente às agências estatais.

Esse modelo encontra, entretanto, limites, particularmente em países em desenvolvimento com suas desigualdades extremas com relação à estrutura de oportunidades, de modo que o Estado continua com uma grande responsabilidade concernente à provisão dos serviços básicos. No entanto, esforços adicionais são indispensáveis para estimular as comunidades locais e as organizações da sociedade civil na busca de estratégias locais apropriadas para superar os problemas sociais.

Uma outra questão fundamental tem a ver com a necessidade de uma renovação das práticas democráticas. Perante a incapacidade das instituições políticas e administrativas tradicionais de solucionar os problemas que afetam o eleitorado, a democracia liberal, sobretudo na sua forma atual, sofre graves problemas de legitimidade política, o que demonstram os recentes números decrescentes de participação nas eleições em boa parte das democracias ocidentais consolidadas.

No futuro deve-se esperar que formas alternativas de participação cidadã, alinhadas às necessidades e expectativas dos cidadãos e das organizações da sociedade civil, desempenharão um papel muito mais importante para a legitimidade política do que o sistema representativo tradicional. A participação política via internet pode-se tornar um canal adicional dentro de uma variedade de novas formas de engajamento cívico e participação democrática. A democracia eletrônica certamente não substituirá a forma tradicional do processo político representativo, mas pode sim complementá-la de uma maneira que novos padrões democráticos possam emergir, ampliando o envolvimento público na deliberação democrática. 
Redes comunitárias, sustentadas por espaços virtuais de deliberação pública, podem contribuir para a criação de capital social. Na sociedade da informação não é a mera densidade de organizações cívicas que determina a capacidade para ação coletiva. Muito mais importante é a efetividade das redes sociais que unem essas organizações e capacitam-nas a agir de maneira coordenada.

Arranjos institucionais e procedimentais correspondentes, que oferecem possibilidades de engajamento cívico e de participação política, são cruciais para assegurar que essas redes cívicas possam alcançar efetividade social e política. $\mathrm{O}$ desenho institucional precisa desempenhar um papel importante na provisão de canais de participação e oportunidades de interação social. Se acompanhadas por medidas que garantam transparência, acesso aberto e participação democrática, comunidades virtuais e redes comunitárias não precisam necessariamente sofrer os perigos de tornar-se excludentes e elitistas. Porém, isso exige, particularmente em comunidades mais pobres, esforços para assegurar acesso e campanhas de qualificação para a população, de modo que esta possa beneficiar-se efetivamente das novas promessas da era digital.

Além disso, desvantagens causadas por uma estrutura desigual de oportunidades e de poder só podem ser mantidas em limites razoáveis se medidas de desenho institucional garantem o estabelecimento de fortes funções de mediação, que no melhor dos casos serão desempenhadas pela sociedade civil e pela esfera pública.

O progresso nessa direção, sobretudo em países com uma sociedade civil pouca organizada, depende ainda da vontade dos governos locais em dar primazia à promoção da emancipação das comunidades e dos cidadãos. Como a experiência dos movimentos sociais e ambientais globais mostra ${ }^{11}$, a estratégia de rede pode ser também uma ferramenta efetiva de resistência e contestação contra as forças dominantes que determinam a atual sociedade em rede. A proliferação de redes comunitárias pode também representar a aspiração das pessoas no que se refere a uma forma renovada de vida social, baseada na confiança e na reciprocidade, capaz de desafiar os processos globais desatados pelas redes transnacionais e hegemônicas das elites econômicas. Sob tais circunstâncias, a opção comunitária pode, de fato, transformar-se em uma alternativa realista na busca de um modo sustentável de desenvolvimento e de vida social.

\footnotetext{
11 Segundo a análise de Castells sobre as redes de movimentos sociais (CASTELLS, 2001, p. 138-143), as quais se originam da resistência de sociedades locais, elas "visam superar o poder das redes globais, assim, reconstruindo o mundo a partir das bases" (idem, p. 143).
}

Klaus Frey (kfrey@rla01.pucpr.br) é Doutor em Ciências Sociais pela Universidade de Konstanz (Alemanha) e Diretor do curso de Mestrado em Gestão Urbana da Pontifícia Universidade Católica do Paraná (PUC-PR).

\section{REFERÊNCIAS BIBLIOGRÁFICAS}

ABERS, R. 1998a. Learning Democratic Practice : Distributing Government Resources through Popular Participation in Porto Alegre, Brazil. In : DOUGLASS M. \& FRIEDMANN, J. (eds.). Cities for Citizens. Planning and the Rise of Civil Society in a Global Age. Chichester : John Wiley \& Sons.

1998b. From Clientelism to Cooperation : Local Government, Participatory Policy, and Civic Organizing in Porto Alegre, Brazil. Politics \& Society, Thousand Oaks, v. 26, n. 4, p. 511537, Dec.
ALMOND, G.A. \& VERBA, S. 1963. The Civic Culture. Princeton : University of Princeton Press.

BAUMAN, Z. 2000. Em busca da política. Rio de Janeiro : Jorge Zahar.

BECK, U. 1988. Die organisierte Unverantwortlichkeit. Frankfurt/Main : Suhrkamp.

1993. Die Erfindung des Politischen. Zu einer Theorie reflexiver Modernisierung. Frankfurt/Main : Suhrkamp. 
BEYME, K. 1992. Die politischen Theorien der Gegenwart. Eine Einführung. Opladen : Westdeutscher Verlag.

BLANCHARD, A. \& HORAN, T. 1998. Virtual Communities and Social Capital. Social Science Computer Review, Thousand Oaks, v. 16, n. 3, p. 293-307, Spring.

BRINT, S. 2001. Gemeinschaft Revisited : A Critique and Reconstruction of the Community Concept. Sociological Theory, Washington, v. 19, n. 1, p. 1-23, Mar.

CARDOSO, R. C. L. 1994. A trajetória dos movimentos sociais. In : DAGNINO, E. (org.). Anos 90 : política e sociedade no Brasil. São Paulo : Brasiliense.

CASTELLS, M. 1994. Space of Flows - Raum der Ströme : Eine Theorie des Raumes in der Informationsgesellschaft. In : NOLLER, P. (org.). Stadt-Welt : Über die Globalisierung Städtischer Milieus. Frankfurt/Main : Campus.

1999. A sociedade em rede. V. 1: A era da informação : economia, sociedade e cultura. São Paulo : Paz e Terra.

2000. Material for an Exploratory Theory of the Network Society. British Journal of Sociology, London v. 51, n. 1, p. 5-24, Jan.-Mar.

2001. The Internet Galaxy. Reflections on the Internet, Business, and Society. Oxford : Oxford University Press,

CLAVELS, P., PITT, J. \& YIN, J. 1997. The Community Option in Urban Policy. Urban Affairs Review, Thousand Oaks, v. 32, n. 4, p. 435-458, Mar.

COLEMAN, S. \& GOTZE, J. 2002. Bowling Together: Online Public Engagement in Policy Deliberation. London: Hansard Society.

DAHLBERG, L. 2001. Extending the Public Sphere through Cyberspace: The Case of Minnesota E-democracy. http://firstmonday.org/issues/issue6_3/dahlberg/. Acesso em : 29.mar.2001.

DOHENY-FARINA, S. 1996. The Wired Neighborhood. New Haven : Yale University Press.

ETZIONI, A. 2001. Is Bowling Together Sociologically Lite? Contemporary Sociology, v. 30, n. 3, p. 223-224, May.
FREY, K. 1996. Crise do Estado e estilos de gestão municipal. Lua Nova, São Paulo, n. 37, p. 107138.

2001a. Perspectivas da democracia local na era digital. Anais do Seminário Brasil-Reino Unido "Cidadania na sociedade da informação”, realizado em 26-28.nov.2001, em Curitiba (PR). Curitiba : Instituto Ágora. http://www.institutoagora.org. Acesso em : jun.2002.

2001b. Building a Local Public Sphere on the Internet to Strengthen Local Democra$c y$ : The Experience of Curitiba/Brazil. Paper presented at the II Global Congress of Citizen Networks, occurred at Buenos Aires, Argentina. www.globalcn2001.org. Acesso em : Jul.2003.

. 2002a. Deliberative Demokratie und städtische Nachhaltigkeit. Konzeptionelle Überlegungen und Erfahrungen aus der brasilianischen Kommunalpolitik. Lateinamerika-Analysen, Hamburgo, v. 1, n. 1, p. 83-113, Fev.

. 2002b. Governança eletrônica. Experiências de cidades européias e algumas lições para países em desenvolvimento. In : EISENBERG, J. \& CEPIK, M. (orgs.). Internet e política. Teoria e prática da democracia eletrônica. Belo Horizonte : UFMG.

GOLDSMITH, A. 1992. Institutions and Planned Socioeconomic Change : Four Approaches. Public Administration Review, v. 52, n. 6, p. 582-587, Nov.-Dec.

GRAHAM, G. 1999. The IInternet : A Philosophical Inquiry. London : Routledge.

GRIX, J. 2001. Social Capital as a Concept in the Social Sciences : The Current State of the Debate. Democratization, London, v. 8, n. 3, p. 189-210, Fall.

GUIDI, L. 2002. Democracia eletrônica em Bolonha. A rede IPERBOLE e a construção de uma comunidade participativa on-line. In : EISENBERG J. \& CEPIK M. (orgs.). Internet e política. Teoria e prática da democracia eletrônica. Belo Horizonte : UFMG.

HIRST, P. 2000. Democracy and Governance. In : PIERRE J. (ed.). Debating Governance : Authority, Steering and Democracy. New York : Oxford University Press. 
HORRIGAN, J. B. 2001. Online Communities : Networks that Nurture Long-distance Relationships and Local Ties. Pew Internet \& American Life Project. http://www.pewInternet.org/. Acesso em : 28.nov.2002.

KOOIMAN, J. 2000. Societal Governance : Levels, Modes, and Orders of Social-political Interaction. In : PIERRE J. (ed.). Debating Governance : Authority, Steering and Democracy. New York : Oxford University Press.

LEVINE, P. 2002. Can the Internet rescue democracy? Toward an on-line commons. http://www.peterlevine.ws/Internetdemocracy.htm. Acesso em : 15.mar.2003.

LOWI, T. J. 1972. Four Systems of Policy, Politics and Choice. Public Administration Review, v. 32, n. 4, p. 298-310, July.-Aug.

LOWNDES, V. \& WILSON, D. 2001. Social Capital and Local Governance : Exploring the Institutional Design Variable. Political Studies, London, v. 49, n. 4, p. 629-647, Sept.

MALONEY, W., SMITH, G. \& STOKER, G. 2000. Social Capital and Urban Governance : Adding a More Contextualised "Top-Down" Perspective. Political Studies, London, v. 48, n. 4, p. 802-820, Sept.

MARCH, J. G. \& OLSEN, J. P. 1994. Institutional Perspectives on Governance. In : DERLIEN, H-U. (ed.). Systemrationalität und Partialinteresse. Festschrift für Renate Mayntz. BadenBaden : Nomos.

MARCH, J. G. \& OLSEN, J. P. 1995. Democratic Governance. New York : Simon \& Schuster.

OAKLEY, K. 2001. Citizenship in the Information Society. Anais do Seminário Brasil-Reino Unido "Cidadania na sociedade da informação", realizado em 26-28.nov.2001, em Curitiba (PR). Curitiba : Instituto Ágora. http:// www.institutoagora.org.br. Acesso em : jul.2002.

O'DONNELL, G. 1991. Democracia delegativa? Novos Estudos CEPRAP, São Paulo, n. 31, p. 25-40.

POSTER, M. 1997. Cyberdemocracy : The Internet and the Public Sphere. In : HOLMES, D. (ed.). Virtual Politics. Identity \& Community in Cyberspace. London : Sage.
PRETTY, J. \& WARD, H. 2001. Social Capital and the Environment. World Development, v. 29, n. 2, p. 209-227.

PRITTWITZ, V. 1994. Politikanalyse. Opladen : Leske + Budrich.

PUTNAM, R. 1993. Making Democracy Work. Civic Traditions in Modern Italy. Princeton, NJ : Princeton University Press.

1995. Bowling Alone: America's Declining Social Capital. Journal of Democracy, Baltimore, v. 6, n. 1, p. 65-78, Jan.

2000a. Comunidade e democracia. A experiência da Itália moderna. Rio de Janeiro : Fundação Getúlio Vargas.

2000b. Bowling Alone: The Collapse and Revival of American Community. New York : Simon and Schuster.

REESE-SCHÄFER, W. 2001. Kommunitarismus. Frankfrut/Main : Campus.

ROESLER, A. 1997. Bequeme Einmischung. Internet und Öffentlichkeit. In : MÜNKER, S. \& ROESLER, A. (orgs.). Mythos Internet. Frankfurt am Main : Suhrkamp.

SANTOS, B.d.S. 1998. Participatory budgeting in Porto Alegre. Towards a redistributive democracy. Politics \& Society. Thousand Oaks, v. 26, n. 4, p. 461-510, Dec.

SASSEN, S. 1997. Cyber-Segmentierungen. Elektronischer Raum und Macht. In : MÜNKER, S. \& ROESLER, A. (orgs.). Mythos Internet. Frankfurt am Main : Suhrkamp.

SCHELSKY, H. 1970. Zur Theorie der Institution. Düsseldorf : Bertelsmann.

SFEZ, L. 2000. Internet et la domination des esprits. Le Monde diplomatique, Paris, n. 52, p. 50-54, Juil.-Août.

TAM, H. 1998. Communitarianism. A New agenda for Politics and Citizenship. London : Macmillan Press.

TELLES, V. S. 1994. Sociedade civil e a construção de espaços públicos. In : DAGNINO, E. (org.). Anos 90 : política e sociedade no Brasil. São Paulo : Brasiliense.

VAN DEN BRINK, B. 1995. Die politischphilosophische Debatte über die demokratische Bürgergesellschaft. In : VAN DEN BRINK, B. 
\& VAN REIJEN W. (orgs.). Bürgergesellschaft, Recht und Demokratie. Frankfurt am Main : Suhrkamp.

WASCHKUHN, A. 1994. Institutionentheoretische Ansätze. In : KRIZ, J. (org.). Politikwissenschaftliche Methoden. Lexikon der Politik. V. 2. München : Beck

WELlMAN, B. 2001. Physical Place and Cyberplace : The Rise of Personalized Networking. International Journal of Urban and Regional Research, Oxford, v. 25, n. 2, p. 227 252, June.
WEYER, J. 2000. Soziale Netzwerke. Konzepte und Methoden der sozialwissenschaftlichen Netzwerkforschung. München/Wien : R. Oldenbourg.

WILSON, J. 2001. Dr. Putnam's Social Lubricant. Contemporary Sociology, v. 30, n. 3, p. 225227, May.

WRIGHT, T. 1996. Reinventing Democracy? In : HIRST, P. \& KHILNANI, S. (eds.). Reinventing Democracy. Oxford: Blackwell. 